\title{
Sertraline-induced pseudocholinesterase enzyme deficiency
}

This article was published in the following Dove Press journal:

International Journal of General Medicine

18 November 2010

Number of times this article has been viewed

\section{Beyazit Zencirci}

MOSTAS Private Health Hospital, Department of Anesthesiology, Kahramanmaras, Turkey
Correspondence: Beyazit Zencirci M. Akif Inan Mah. Alparslan Turkes Bulvari, Seyhan Apt. No: 209 D: 5, Merkez-Kahramanmaras, Turkey Tel $+90344-2258300$

Fax +90 344-2258303

Email bzencirci@fastmail.fm

\begin{abstract}
A 47-year-old Turkish male was scheduled for laparoscopic cholecystectomy under general anesthesia. The patient had 2 operations 28 and 19 years ago under general anesthesia. It was learned that the patient was administered succinylcholine during both of these previous operations and that he did not have a history of prolonged recovery or postoperative apnea. The patient had been using sertraline for 3 years before the operation. Pseudocholinesterase is a drug-metabolizing enzyme responsible for hydrolysis of the muscle-relaxant drugs mivacurium and succinylcholine. Deficiency of this enzyme from any cause can lead to prolonged apnea and paralysis following administration of mivacurium and succinylcholine. The diagnosis of pseudocholinesterase enzyme deficiency can be made after careful clinic supervision and peripheral nerve stimulator monitoring. A decrease in the activity of pseudocholinesterase enzyme and a decline in the block effect over time will help verify the diagnosis. Our patient's plasma cholinesterase was found to have low activity. Instead of pharmacological interventions that may further complicate the situation in such cases, the preferred course of action should be to wait until the block effect declines with the help of sedation and mechanical ventilation. In our case, the prolonged block deteriorated in the course of time before any complications developed.
\end{abstract}

Keywords: mivacurium, pseudocholinesterase deficiency, sertraline

\section{Introduction}

Pseudocholinesterase (PCHE) is an enzyme with a complex molecular structure. ${ }^{1}$ It is synthesized in the liver and immediately released into the plasma. ${ }^{2}$ The plasma half-life has been estimated to be approximately 12 days. ${ }^{3}$ Deficiency or reduced activity of this enzyme results in significant prolongation of mivacurium- or succinylcholine-induced neuromuscular blockade. ${ }^{4}$ In addition, a number of disease states or concomitant drug administration may reduce PCHE activity.

Mivacurium, which is a nondepolarizing neuromuscular blocking drug administered in doses of 0.1 to $0.2 \mathrm{mg} / \mathrm{kg}$, also produces rapid onset of neuromuscular blockade lasting for 15 to 30 minutes. ${ }^{5}$ The rapid ester hydrolysis of mivacurium by PCHE results in the short duration of action of this drug, which is ideal for providing muscle relaxation for brief surgical procedures. ${ }^{6}$ But the duration of mivacurium of action in adults is inversely related to serum PCHE activity.,

Sertraline is an antidepressant and antipanic agent that is a potent and selective inhibitor of serotonin reuptake into the presynaptic terminals. It has relatively weak effects on the cytochrome P450 system, a tolerability profile that is positive compared with antidepressants of other classes, and it is relatively safe in overdose. These findings 
contribute to sertraline being the first-line agent for the treatment of several psychiatric disorders. ${ }^{9}$ It was shown, however, that sertraline and other antidepressants inhibited acetylthiocholine hydrolysis by cholinesterases in human serum and erythrocyte membrane. ${ }^{10}$

In this article, we share our experience of a case with acquired pseudocholinesterase enzyme deficiency due to sertraline use, and provide a literature review.

\section{Case report*}

A 47-year-old Turkish male, $83 \mathrm{~kg}$ in weight and $175 \mathrm{~cm}$ in height, was scheduled for laparoscopic cholecystectomy (due to cholecystitis with an acute stone) under general anesthesia. Under general anesthesia, the case had an appendectomy 28 years ago and a right inguinal hernia operation 19 years ago. It was learned that the patient was administered succinylcholine during both these operations and that he did not have a history of prolonged recovery or postoperative apnea. Except for alkaline phosphatase (ALP) (176 U/L), alanine aminotransferase (ALT) (52 U/L) and a minimal increase in aspartate aminotransferase (AST) $(61 \mathrm{U} / \mathrm{L})$, and a slight leucocytosis $\left(9.8 \times 10^{9} / \mathrm{L}\right)$, no other pathologies were identified during preoperative laboratory investigation. The patient had been using sertraline (100 mg/day) for 3 years for major depressive disorder.

Following preoxygenation, induction of anesthesia was achieved with $200 \mathrm{mg}$ of propofol. Tracheal intubation was achieved with $17 \mathrm{mg}$ of mivacurium. Isoflurane was used as the general anesthetic inhalation agent. The operation lasted for 30 minutes and the surgery was uneventful. After surgery, the inhalation agent was discontinued, the patient received $100 \%$ oxygen but there was no clinical evidence of neuromuscular function recovery and there was no response to train-of-four stimulation. Peripheral nerve stimulator (PNS) produced zero twitches. Anesthesia was therefore maintained with $0.5 \%$ isoflurane in $50 \%$ nitrous oxide and oxygen because there was no evidence of improved neuromuscular function 50 minutes after administration of mivacurium. All vital signs were stable, and oxygen saturation remained $100 \%$. After an additional 20 minutes, a PCHE deficiency was suspected. Five milligrams of midazolam was administered intravenously for its sedative and amnestic effects. Later the patient was transferred to the Post-anesthesia Care Unit (PACU) for observation

"Monitoring included electrocardiography (ECG), noninvasive arterial blood pressure (NIBP), oxygen saturation $\left(\mathrm{SpO}_{2}\right)$, capnography $\left(\mathrm{ETCO}_{2}\right)$, and peripheral nerve stimulator (PNS) monitoring applied over the ulnar nerve in this case. and ventilator support. Spontaneous muscle twitching was noted 2 hours and 20 minutes later. Train-of-four response ratio was $75 \% 2$ hours and 55 minutes after mivacurium administration.

The patient regained sufficient motor function to meet extubation requirements 3 hours and 15 minutes after the initial use of mivacurium. Midazolam infusion was discontinued and clinical assessment confirmed recovery of neuromuscular function. The patient was extubated for 205 minutes following the administration of mivacurium and further recovery was uneventful. Plasma cholinesterase was found to have very low activity (788 IU/L). The patient was transferred to a hospital ward for the evening and was discharged 4 days later.

\section{Discussion}

Mivacurium is a potent benzylisoquinoline, nondepolarizing, neuromuscular blocking drug. A recommended intravenous dose of 0.15 to $0.2 \mathrm{mg} / \mathrm{kg}$ provides tracheal intubating conditions within 2 to 2.5 minutes, with a predicted duration of action of 15 to 25 minutes, making it an ideal drug for short procedures requiring tracheal intubation. ${ }^{11}$ It is a structural relative of atracurium, but it does not undergo Hofmann elimination and is rapidly hydrolyzed by PCHE. The activity of PCHE affects its duration of action. ${ }^{4}$

PCHE is a tetrameric glycoprotein enzyme produced by the liver, which hydrolyzes choline esters such as those found in succinylcholine, mivacurium, procaine, chloroprocaine, tetracaine, cocaine, and heroine. ${ }^{12}$ In patients with a normal genotype for PCHE, mivacurium's duration of action is inversely related to PCHE activity and duration of action is slightly prolonged if activity is low. ${ }^{13}$

When there is a deficiency of this enzyme due to the presence of one or more atypical alleles, mivacurium is not properly metabolized and thus muscle paralysis can last for several hours. There are 2 forms of inherited atypical pseudocholinesterase deficiency. The heterozygous atypical form affects from 1 in 25, to 1 in 480 individuals (depending on the severity of the condition). ${ }^{12}$ Patients heterozygous for an abnormal enzyme may show up to $50 \%$ prolongation of block. ${ }^{13}$ In patients homozygous for an abnormal enzyme, duration may be significantly prolonged, and even a small dose (eg, $0.03 \mathrm{mg} / \mathrm{kg}$ ) can result in complete paralysis for up to 128 minutes. ${ }^{14}$ There are now several case reports in the literature of prolonged block following mivacurium administration.

Different disease states and/or drug administrations may affect PCHE activity. Physiological reductions may 
occur with extremes of age and during pregnancy. ${ }^{15}$ Other acquired causes of decreased activity include renal and liver disease, malignancy, burns, chronic debilitation/malnutrition, myocardial infarction/cardiac failure, collagen diseases, myxedema, and organophosphate poisoning. ${ }^{16}$ Plasma cholinesterase levels in human subjects with protein energy malnutrition have been investigated. ${ }^{17}$

Drugs that inhibit the enzyme's activity include acetylcholinesterase inhibitors (neostigmine, pyridostigmine, physostigmine, and edrophonium), anticholinesterases (especially echothlophate), cytotoxic agents (such as cyclophosphamide), steroids, ester-type local anesthetics, hexafluorenium, pancuronium, and oral contraceptives. ${ }^{18}$

Our patient previously had 2 operations under general anesthesia with succinylcholine. However, a prolonged apnea and low enzyme activity (788 IU/L) was present in the operation reported here. Although the patient had not had any problems during the previous operations, absence of a medical history proving the existence of the same problem in close relatives led us to think that this was an acquired PCHE deficiency. At this stage, we at once started to implement an algorithm which is usually used in cases of PCHE deficiency. At this stage, we also started to examine the causes of acquired PCHE deficiency thoroughly. However, we noted that the medical conditions (such as extremes of age, pregnancy) and problems (such as renal and liver disease, malnutrition) reported in the literature that we have tried to summarize above did not match our case. Therefore, we considered the drugs known to affect PCHE activity that the patient may have been taking. We discovered that the patient had been using sertraline $(100 \mathrm{mg} /$ day $)$ for 3 years due to depression.

Sertraline is a serotonin reuptake inhibitor (SSRI) that is indicated for the treatment of depression. With therapeutic doses, side effects are minimal. Sertraline has a wide therapeutic index and appears to be safer than the tricyclic antidepressants in overdose. ${ }^{19}$ The usual clinical antidepressants (fluoxetine, sertraline, and amitriptyline) are, however, inhibitors of the cholinesterases in human serum and erythrocyte membrane. Antidepressants exhibit this inhibiting effect by reversibly attaching to the enzyme's bottom of the active site gorge, and the collapse of the product (eg, mivacurium or succinylcholine) being hydrolyzed by the enzyme decreases during this process of attachment. ${ }^{10}$ The order of inhibitory potency was sertraline $>$ amitriptyline $>>$ fluoxetine. The concentrations of antidepressants necessary to inhibit serum cholinesterase are relatively close to the clinical levels found after pharmacological use of sertraline and amitriptyline.
Consequently, undesirable pharmacological and toxicological side effects of these antidepressants can be related, at least in part, to inhibition of serum and erythrocyte cholinesterases. ${ }^{10}$ Therefore, chronic enzyme inhibition which might have developed due to 3 years of use of sertraline in our patient led to a significant and marked prolongation in the activity time of the neuromuscular blocking agent metabolized by this enzyme.

The results achieved by Müller et $\mathrm{al}^{10}$ corroborated our suspicions about sertraline. Also, the retested (3 months after the operation) PCHE value (2762 IU/L) was seen to have returned to normal after the patient gave up using sertraline under the supervision of a psychiatrist. We did not discover any case that implied an interaction between sertraline and pseudocholinesterase in our literature review, and we believe this is the first presentation of such a case.

When we understood that we were dealing with a case of acquired PCHE deficiency, we made our treatment plan. Our main aim was to administer a supportive treatment to the patient until enzyme activity returned to normal. Therefore we did not consider a blood transfusion (considering the risks of blood transfusion, such as allergic reactions, infection, fever reaction). We also avoided administering drugs (such as calcium, neostigmine) that might complicate the present condition. The clinician should be especially aware that administering neostigmine to a patient with prolonged mivacurium-induced block will inhibit plasma cholinesterase activity. Therefore, blood should not be drawn for cholinesterase activity until the effect of neostigmine dissipates. In our case, when we suspected PCHE deficiency, together with PNS findings, we sent the blood samples to the laboratory for enzyme analysis. Consequently, we supported our case solely with sedation, mechanical ventilation, and PNS monitoring, and without neostigmine application.

\section{Conclusion}

Prolonged blocks may be encountered as a result of PCHE enzyme deficiency when mivacurium is used. In our case, this situation was due to sertraline, which is commonly administered for various psychiatric disorders, particularly depression.

In this context, we believe two issues should be highlighted. Firstly, while examining the drugs used by patients during preoperative anesthesia anamnesis, next-generation antidepressants (especially SSRIs) should not be ignored. As in the case reported, this group of drugs, known to have a wide safety margin, may cause casual and unexpected block prolongation when used along with drugs (mivacurium and 
succinylcholine) that are hydrolyzed especially by PCHE activity during anesthesia.

Secondly, in these situations, attempted reversal of the block was at best only partially successful, and the patients were partially paralyzed and minimally sedated while attempts were made to have them breathe - a very unpleasant experience. In cases of prolonged block, no reversal was attempted. The patients were kept sedated, and their lungs mechanically ventilated until the block recovered spontaneously, and then extubated without problem.

\section{Disclosure}

The author reports no conflicts of interest.

\section{References}

1. Lockridge O, Bartels CF, Vaughan TA, Wong CK, Norton SE, Johnson LJ. Complete amino acid sequence of human serum cholinesterase. $J$ Biol Chem. 1987;262:549-557.

2. Pedersen NA, Jensen FS. Clinical importance of plasma cholinesterase for the anaesthetist. Ann Acad Med Singapore. 1994;23 Suppl:120-124.

3. Ostergaard D, Viby-Mogensen J, Hanel HK, Skovgaard LT. Halflife of plasma cholinesterase. Acta Anaesthesiol Scand. 1988;32:266-269.

4. Cerf C, Mesguish M, Gabriel I, Amselem S, Duvaldestin P. Screening patients with prolonged neuromuscular blockade after succinylcholine and mivacurium. Anesth Analg. 2002;94:461-466.

5. Ali HH, Savarese JJ, Embree PB, et al. Clinical pharmacology of mivacurium chloride (BW B1090U) infusion: comparison with vecuronium and atracurium. Br J Anaesth. 1988;61:541-546.

6. Savarese JJ, Lien CA, Belmont MR, Wastila WB. The clinical pharmacology of new benzylisoquinoline-diester compounds. with special consideration of cisatracurium and mivacurium. Anesthetist. 1997;46:840-849.
7. Petersen RS, Bailey PL, Kalameghan R, Ashwood ER. Prolonged neuromuscular block after mivacurium. Anesth Analg. 1993;76: 194-196.

8. Goudsouzian NG, d'Hollander AA, Viby-Mogensen J. Prolonged neuromuscular block from mivacurium in two patients with cholinesterase deficiency. Anesth Analg. 1993;77:183-185.

9. MacQueen G, Born L, Steiner M. The selective serotonin reuptake inhibitor sertraline: its profile and use in psychiatric disorders. CNS Drug Rev. 2001;7:1-24.

10. Müller TC, Rocha JB, Morsch VM, Neis RT, Schetinger MR. Antidepressants inhibit human acetylcholinesterase and butyrylcholinesterase activity. Biochim Biophys Acta. 2002;1587:92-98.

11. Frampton JE, McTavish D. Mivacurium. A review of its pharmacology and therapeutic potential in general anaesthesia. Drugs. 1993;45: 1066-1089.

12. Pantuck E. Plasma cholinesterase: gene and variations. Anesth Analg. 1993;77:380-386.

13. Ostergaard D, Jensen FS, Jensen E, Skovgaard LT, Viby-Mogensen J. Influence of plasma cholinesterase activity on recovery from mivacurium-induced neuromuscular blockade in phenotypically normal patients. Acta Anaesthesiol Scand. 1992;36:702-706.

14. Ostergaard D, Jensen FS, Jensen E, Skovgaard LT, Viby-Mogensen J. Mivacurium-induced neuromuscular blockade in patients with atypical plasma cholinesterase. Acta Anaesthesiol Scand. 1993;37:314-318.

15. Jensen FS, Viby-Morgensen J, Ostergaard D. Significance of plasma cholinesterase for the anaesthetist. Curr Anaesth Crit Care. 1991;2: 232-237.

16. Davis L, Britten JJ, Morgan M. Cholinesterase. Its significance in anaesthetic practice. Anaesthesia. 1997;52:244-260.

17. Kumari R, Rao YN, Talukdar B, Agarwal S, Puri RK. Serum enzyme abnormalities in protein energy malnutrition. Ind Pediatr. 1993;30: 469-473.

18. Hunter JM. Muscle function and neuromuscular blockade. In: Aitkenhead AR, Rowbotham DJ, Smith G, editors. Textbook of Anesthesia 4th ed. Spain; Churchill Livingstone; 2001:223-237.

19. Klein-Schwartz W, Anderson B. Analysis of sertraline-only overdoses. Am J Emerg Med. 1996;14:456-458.
International Journal of General Medicine

\section{Publish your work in this journal}

The International Journal of General Medicine is an international, peer-reviewed open-access journal that focuses on general and internal medicine, pathogenesis, epidemiology, diagnosis, monitoring and treatment protocols. The journal is characterized by the rapid reporting of reviews, original research and clinical studies across all disease areas.

\section{Dovepress}

A key focus is the elucidation of disease processes and management protocols resulting in improved outcomes for the patient.The manuscript management system is completely online and includes a very quick and fair peer-review system. Visit http://www.dovepress.com/ testimonials.php to read real quotes from published authors. 